\title{
Isocitrate dehydrogenase mutation in Vibrio anguillarum results in virulence attenuation and immunoprotection in rainbow trout (Oncorhynchus mykiss)
}

Xiangyu Mou ${ }^{1,2 \dagger}$, Edward J. Spinard ${ }^{1 \dagger}$, Shelby L. Hillman ${ }^{1}$ and David R. Nelson ${ }^{1 *}$

\begin{abstract}
Background: Vibrio anguillarum is an extracellular bacterial pathogen that is a causative agent of vibriosis in finfish and crustaceans with mortality rates ranging from 30\% to 100\%. Mutations in central metabolism (glycolysis and the TCA cycle) of intracellular pathogens often result in attenuated virulence due to depletion of required metabolic intermediates; however, it was not known whether mutations in central metabolism would affect virulence in an extracellular pathogen such as $V$. anguillarum.
\end{abstract}

Results: Seven central metabolism mutants were created and characterized with regard to growth in minimal and complex media, expression of virulence genes, and virulence in juvenile rainbow trout (Oncorhynchus mykiss). Only the isocitrate dehydrogenase (icd) mutant was attenuated in virulence against rainbow trout challenged by either intraperitoneal injection or immersion. Further, the icd mutant was shown to be immunoprotective against wild type $V$. anguillarum infection. There was no significant decrease in the expression of the three hemolysin genes detected by qRT-PCR. Additionally, only the icd mutant exhibited a significantly decreased growth yield in complex media. Growth yield was directly related to the abundance of glutamate. A strain with a restored wild type icd gene was created and shown to restore growth to a wild type cell density in complex media and pathogenicity in rainbow trout.

Conclusions: The data strongly suggest that a decreased growth yield, resulting from the inability to synthesize a-ketoglutarate, caused the attenuation despite normal levels of expression of virulence genes. Therefore, the ability of an extracellular pathogen to cause disease is dependent upon the availability of hostsupplied nutrients for growth. Additionally, a live vaccine strain could be created from an icd deletion strain.

Keywords: Vibrio anguillarum, TCA cycle, Vibriosis, Isocitrate dehydrogenase, Virulence, Hemolysin

\section{Background}

The aquaculture industry now produces half of all fish intended for human consumption and employs millions of people worldwide [1]. Although the first value sale of harvested fish has increased by $267 \%$ between 2004 and 2014 to over US\$160 billion, infectious diseases, especially those caused by Vibrio spp. including Vibrio anguillarum, still represent a major impediment to the

\footnotetext{
* Correspondence: dnelson@uri.edu

${ }^{\dagger}$ Equal contributors

'Department of Cell and Molecular Biology, University of Rhode Island,

Kingston, RI 02881, USA

Full list of author information is available at the end of the article
}

production of fish [1]. $V$. anguillarum causes diseases in crustaceans and bivalves, and is the leading causative agent of vibriosis in finfish including salmon, rainbow trout, turbot, sea bass, sea bream, cod, eel, and ayu [2]. Infections by this bacterial species have resulted in severe economic losses to aquaculture industries worldwide [3].

$V$. anguillarum is an extracellular pathogen that invades its host fish through the intestine, skin or gills $[4,5]$. Systemic infection by $V$. anguillarum usually causes fish to die within 1-4 days [6-9]. Chemotactic motility and the metalloprotease EmpA have been 
shown to be important virulence factors during the invasion stage while the siderophore anguibactin, flagellin subunits and lipopolysaccharides were shown to be important for persistence in the host during the postinvasion stage $[2,10]$. Three secreted proteins that are cytotoxic against epithelial cells and erythrocytes have been characterized in $V$. anguillarum: the HlyA homolog Vah1, the phospholipase Plp, and the MARTX toxin RtxA [7, 9, 11]. Mutations in vah1 and/or plp resulted in slight attenuation against juvenile Atlantic salmon (Salmo salar); however, $r t x A$ mutants were avirulent $[7,9,11]$. Additionally, a $V$. anguillarum mutant that lacks H-NS, a global transcriptional regulator that represses the transcription of vah1, plp, and $r t x A$, showed attenuation in virulence when injected intraperitoneally, suggesting that proper coordination of gene expression is an important factor during the post-invasion stage [8].

Since the 1980s, several bacterial species that are auxotrophic for aromatic compounds have been shown to be avirulent [12-16]. More recently, mutants that are hypothesized to experience growth defects in the nutrient limited environment inside a phagocyte have been characterized. In Salmonella enterica, an intracellular bacterial pathogen, some tricarboxylic acid (TCA) cycle mutant strains were avirulent and immunoprotective for subsequent wild-type S. enterica infection [17-21]. A functional fructose repressor (Cra) was also required for $S$. enterica infection [22]. Similar results have been observed for central metabolism mutants in other intracellular pathogens such as uropathogenic Escherichia coli (UPEC), Mycobacterium tuberculosis, and the facultative intracellular fish pathogen Edwardsiella ictaluri [23-27]. These observations demonstrate that central metabolism is important for pathogenesis by intracellular pathogens.

Accordingly, we hypothesized that mutations in central metabolism could interrupt the infection process of $V$. anguillarum in juvenile rainbow trout (Oncorhynchus mykiss). In this study, we identified and created six TCA cycle mutant strains plus one fructose metabolism mutant strain, and tested their virulence against juvenile rainbow trout using two infection methods, intraperitoneal (IP) injection and immersion. Further, the expression of each of the three hemolysin genes ( $v a h 1, p l p$, and $r t x A$ ) was examined to determine whether attenuation resulted from decreased virulence factor expression in these mutants. The growth rates and yield of each mutant strain in complex media were also determined. We specifically characterized the growth defect of the attenuated icd mutant. We also created, tested, and compared a restored wild type icd strain for virulence and growth to both the wild type and the icd mutant.

\section{Methods}

Bacterial strains, plasmids and growth conditions

$V$. anguillarum strains (Table 1) were routinely grown in Lysogeny broth containing $2 \% \mathrm{NaCl}$ (LB20) [28] or Marine Minimum Median (3M) $+0.15 \%$ glucose [29], supplemented with the appropriate antibiotic, in a shaking water bath at $27{ }^{\circ} \mathrm{C}$. E. coli strains (Table 1) were routinely grown in Lysogeny broth containing $1 \% \mathrm{NaCl}$ (LB10) supplemented with the appropriate antibiotic, in a shaking water bath at $37{ }^{\circ} \mathrm{C}$. Antibiotics were used at the following concentrations: streptomycin, $200 \mu \mathrm{g} / \mathrm{ml}$ $\left(\mathrm{Sm}^{200}\right)$; chloramphenicol, $20 \mu \mathrm{g} / \mathrm{ml}\left(\mathrm{Cm}^{20}\right)$ for E. coli and $5 \mu \mathrm{g} / \mathrm{ml}\left(\mathrm{Cm}^{5}\right)$ for $V$. anguillarum; kanamycin, 50 $\mu \mathrm{g} / \mathrm{ml}\left(\mathrm{Km}^{50}\right)$ for E. coli and $80 \mu \mathrm{g} / \mathrm{ml}\left(\mathrm{Km}^{80}\right)$ for $V$. anguillarum.

\section{Identification of genes in V. anguillarum}

$V$. anguillarum M93Sm draft genome (accession number NOWD00000000) was annotated by the RAST (Rapid Annotation using Subsystem Technology) service (http:// rast.nmpdr.org/rast.cgi) using the default settings [30]. The following annotated genomes were downloaded from NCBI: $V$. anguillarum 775 (accession numbers: NC_015 633.1 and NC_015637.1), 96F (accession number: NZ_AE ZA00000000.1), M3 (accession numbers: NC_022223.1, NC_022224.1 and NC_022225.1), NB10 (accession numbers: NZ_LK021130.1, NZ_LK021129.1 and NZ_LK0 21128.1), RV22 (accession number: AEZB00000000.1) and 90-11-286 (accession numbers: NZ_CP011460.1 and NZ_CP011461.1).

\section{Insertional mutagenesis}

Insertional mutations were made by using a modification of the procedure described by Milton et al. [31]. Briefly, primers (Table 2) were designed based on the target gene sequence of M93Sm. An internal 200-300 bp DNA fragment of the first third of the target gene was PCR amplified and ligated into the suicide vector pNQ705-1 (Table 1) after digestion with SacI and XbaI. The ligation mixture was introduced into E. coli SM10 by electroporation using a BioRad Gene Pulser II (BioRad, Hercules, CA). Transformants were selected on LB10 $\mathrm{Cm}^{20}$ agar plates. The construction of the recombinant pNQ705 was confirmed by both PCR amplification and restriction enzyme analysis. The mobilizable suicide vector was transferred from E. coli SM10 into $V$. anguillarum by conjugation [32]. Transconjugants were selected by utilizing the chloramphenicol resistance gene located on the suicide plasmid. The incorporation of the recombinant pNQ705 was confirmed by PCR amplification.

\section{Fish infection experiments}

Various $V$. anguillarum strains were tested for virulence against rainbow trout (O. mykiss) by intraperitoneal (IP) 
Table 1 Bacterial strains and plasmids used in this study

\begin{tabular}{|c|c|c|}
\hline Strain or plasmid & Description & Reference \\
\hline \multicolumn{3}{|c|}{ V. anguillarum strains } \\
\hline M93Sm & $\begin{array}{l}\text { Spontaneous } \mathrm{Sm}^{\mathrm{r}} \text { mutant of } \mathrm{M} 93 \\
\text { (serotype O2a) }\end{array}$ & [47] \\
\hline XM420 & $\mathrm{Sm}^{r} \mathrm{Cm}^{r}$; icd insertional mutant & This study \\
\hline ES422 & $\mathrm{Sm}^{\mathrm{r}}$; Restored icd strain & This study \\
\hline XM440 & $\mathrm{Sm}^{r} \mathrm{Cm}^{\mathrm{r}}$; sucA insertional mutant & This study \\
\hline XM450 & $\mathrm{Sm}^{r} \mathrm{Cm}^{\mathrm{r}}$; sucC insertional mutant & This study \\
\hline XM460 & $\mathrm{Sm}^{\mathrm{r}} \mathrm{Cm}^{\mathrm{r}}$; sdhC insertional mutant & This study \\
\hline XM470 & $\mathrm{Sm}^{r} \mathrm{Cm}^{\mathrm{r}}$; fumA insertional mutant & This study \\
\hline $\mathrm{XM} 410$ & $\mathrm{Sm}^{\mathrm{r}} \mathrm{Cm}^{\mathrm{r}}$; mdh insertional mutant & This study \\
\hline XM430 & $\mathrm{Sm}^{r} \mathrm{Cm}^{r}$; $\mathrm{cra}$ insertional mutant & This study \\
\hline \multicolumn{3}{|l|}{ E. coli strains } \\
\hline SM10 & $\begin{array}{l}\text { thi thr leu tonA lacY supE recA } \\
\text { RP4-2-Tc::Mu::Km ( } \lambda \text { pir) }\end{array}$ & [48] \\
\hline 5100 & $\begin{array}{l}\mathrm{Km}^{\mathrm{r}} ; \text { Sm10 containing plasmid } \\
\mathrm{pNQ705-1}\end{array}$ & [49] \\
\hline Q420 & $\begin{array}{l}\mathrm{Km}^{\mathrm{r}} \mathrm{Cm}^{\mathrm{r}} \text {; Sm10 containing } \\
\text { plasmid pNQ705-icd }\end{array}$ & This study \\
\hline Q440 & $\begin{array}{l}\mathrm{Km}^{\mathrm{r}} \mathrm{Cm}^{\mathrm{r}} \text {; Sm } 10 \text { containing } \\
\text { plasmid pNQ705-sucA }\end{array}$ & This study \\
\hline Q450 & $\begin{array}{l}\mathrm{Km}^{\mathrm{r}} \mathrm{Cm}^{\mathrm{r}} \text {; Sm10 containing } \\
\text { plasmid pNQ705-sucC }\end{array}$ & This study \\
\hline Q460 & $\begin{array}{l}\mathrm{Km}^{\mathrm{r}} \mathrm{Cm}^{\mathrm{r}} \text {; Sm } 10 \text { containing } \\
\text { plasmid pNQ705-sdhC }\end{array}$ & This study \\
\hline Q470 & $\begin{array}{l}\mathrm{Km}^{\mathrm{r}} \mathrm{Cm}^{\mathrm{r}} \text {; Sm } 10 \text { containing } \\
\text { plasmid pNQ705-fumA }\end{array}$ & This study \\
\hline Q410 & $\begin{array}{l}\mathrm{Km}^{\mathrm{r}} \mathrm{Cm}^{\mathrm{r}} \text {; Sm } 10 \text { containing } \\
\text { plasmid pNQ705-mdh }\end{array}$ & This study \\
\hline Q430 & $\begin{array}{l}\mathrm{Km}^{\mathrm{r}} \mathrm{Cm}^{\mathrm{r}} \text {; Sm10 containing } \\
\text { plasmid pNQ705-cra }\end{array}$ & This study \\
\hline \multicolumn{3}{|l|}{ Plasmid } \\
\hline pNQ705-1 & $\mathrm{Cm}^{r}$; suicide vector with R6K origin & [49] \\
\hline pNQ705-icd & $\mathrm{Cm}^{r}$; For icd insertional mutant & This study \\
\hline pNQ705-sucA & $\mathrm{Cm}^{\mathrm{r}}$; For sucA insertional mutant & This study \\
\hline pNQ705-sucC & $\mathrm{Cm}^{r}$; For sucC insertional mutant & This study \\
\hline pNQ705-sdhC & $\mathrm{Cm}^{r}$; For sdhC insertional mutant & This study \\
\hline pNQ705-fumA & $\mathrm{Cm}^{\mathrm{r}}$; For fumA insertional mutant & This study \\
\hline pNQ705-mdh & $\mathrm{Cm}^{r}$; For mdh insertional mutant & This study \\
\hline pNQ705-cra & $\mathrm{Cm}^{r}$; For cra insertional mutant & This study \\
\hline
\end{tabular}

injection or immersion. Briefly, $V$. anguillarum cells grown for $19 \mathrm{~h}$ at $27^{\circ} \mathrm{C}$ in LB20 supplemented with the appropriate antibiotics were harvested by centrifugation $\left(9000 \times g, 5 \mathrm{~min}, 4^{\circ} \mathrm{C}\right)$, washed twice in nine salts solution (NSS), and resuspended in NSS [33, 34]. Aliquots $(100 \mu \mathrm{l})$ of the $V$. anguillarum NSS suspension were used to determine the $\mathrm{OD}_{600}$. The $V$. anguillarum NSS suspension was prepared to the desired specific cell density according to the conversion equation as determined by experimentation (data not shown): Cell density $\left(10^{8} \mathrm{CFU} / \mathrm{ml}\right)=44.905 \times \mathrm{OD}_{600}$. The actual cell density of the suspension was confirmed by dilution and viable plate count. All fish were examined and determined to be disease and injury free prior to the start of each experiment. For IP injection, fish were anesthetized by tricaine methanesulfonate (Western Chemical, Ferndale, WA), (100 mg/l for induction and $52.5 \mathrm{mg} / \mathrm{l}$ for maintenance). $V$. anguillarum strains were IP injected into fish that were between 15 and $25 \mathrm{~cm}$ long in a $100 \mu \mathrm{l}$ NSS vehicle at a dose of either $2 \times 10^{5}$ or $4 \times$ $10^{5} \mathrm{CFU} /$ fish, or with NSS only as a negative control. For immersion, $10 \mathrm{ml}$ of $V$. anguillarum suspended in NSS, or $10 \mathrm{ml}$ of NSS only as a negative control was added to a bucket filled with $10 \mathrm{~L}$ of water supplemented with $1.5 \% \mathrm{NaCl}$ that was maintained at $18 \pm$ $1{ }^{\circ} \mathrm{C}$. Fish that were between 15 and $25 \mathrm{~cm}$ long were added and immersed for $1 \mathrm{~h}$. For both methods, fish inoculated with different bacterial strains were maintained in separate 10-gal (38 L) tanks to prevent possible cross-contamination with constant water flow $(200 \mathrm{ml} / \mathrm{min})$ at $18 \pm 1{ }^{\circ} \mathrm{C}$. Death due to vibriosis was determined by the observation of gross clinical symptoms and confirmed by the recovery and isolation of $V$. anguillarum cells resistant to the appropriate antibiotics from the spleen or head kidney of dead fish. Observations were made for 8-14 days. All fish used in this research project were obtained from the URI East Farm Aquaculture Center. All fish infection protocols were approved by the URI IACUC. (IACUC Protocol AN06-08-002).

\section{RNA isolation}

Exponential phase cells $\left(\sim 0.5 \times 10^{8} \mathrm{CFU} / \mathrm{ml}\right)$ of various $V$. anguillarum strains were treated with RNAprotect Bacteria Reagent (QIAGEN), following the manufacturer's instructions. Total RNA was isolated using the RNeasy kit and QIAcube (QIAGEN) following the instructions of the manufacturer. All purified RNA samples were quantified spectrophotometrically by measuring absorption at $260 \mathrm{~nm}$ and $280 \mathrm{~nm}$ using a NanoDrop ND-1000 spectrophotometer (Thermo Fisher Scientific) and overall quality was assessed by gel electrophoresis. Samples were stored at $-75^{\circ} \mathrm{C}$ for future use.

\section{Real-time quantitative RT-PCR (qRT-PCR)}

qRT-PCR was used to quantify various mRNAs using an LightCycler $^{\oplus} 480$ Real-Time PCR System (Hoffmann-La Roche Inc.) and the Brilliant II SYBR Green Single-Step QRT-PCR Master Mix (Agilent Technologies), with $10 \mathrm{ng}$ of total RNA in $20 \mu \mathrm{l}$ reaction mixtures. The thermal profile was $50{ }^{\circ} \mathrm{C}$ for $30 \mathrm{~min}, 95{ }^{\circ} \mathrm{C}$ for $15 \mathrm{~min}$, and then 40 cycles of $95{ }^{\circ} \mathrm{C}$ for $30 \mathrm{~s}$ and $55^{\circ} \mathrm{C}$ for $30 \mathrm{~s}$. Fluorescence was measured at the end of the $55{ }^{\circ} \mathrm{C}$ stage 
Table 2 Primers used in this study

\begin{tabular}{|c|c|c|c|}
\hline Primer & $\begin{array}{l}\text { Sequence ( } 5^{\prime} \text { to } 3^{\prime} \text {, underlined sequences are designed } \\
\text { restriction sites) }\end{array}$ & Description & Reference \\
\hline pr31 & GGTGAGCTCTATTCTTTATTGCCGATTATC & For icd insertional mutant, forward, Sacl & This study \\
\hline pr32 & AAATCTAGAGTAAGTCGCTITAATCGCTTC & For icd insertional mutant, reverse, Xbal & This study \\
\hline pr50 & AAAGAGCTCGTGATCCAGATGTCGATGCTA & For sucA insertional mutant, forward, Sacl & This study \\
\hline pr51 & GGTTCTAGAGTTCAGTGTCGATAATGTGCA & For sucA insertional mutant, reverse, $X b a l$ & This study \\
\hline pr52 & AAAGAGCTCGGTCGGATTAGTACAGCGAAG & For sucC insertional mutant, forward, Sacl & This study \\
\hline pr53 & GGTTCTAGACTITITCAATTTCCACGCCGC & For sucC insertional mutant, reverse, $\mathrm{Xbal}$ & This study \\
\hline pr54 & AAAGAGCTCATGTTCGTTGCGGTCGGAATT & For sdhC insertional mutant, forward, Sacl & This study \\
\hline pr55 & GGTTCTAGATCCAACTCTTCAAAGTGGCCC & For sdhC insertional mutant, reverse, $X b a l$ & This study \\
\hline pr56 & GGTGAGCTCTCCTTGCACCATATTGATATG & For fumA insertional mutant, forward, Sacl & This study \\
\hline pr57 & GGGTCTAGAAGGCTTATCATCGAGAAGAGAG & For fumA insertional mutant, reverse, $X b a l$ & This study \\
\hline pr29 & GGTGAGCTCATGCCAGCGTTAACATTAAAC & For mdh insertional mutant, forward, Sacl & This study \\
\hline pr30 & AAATCTAGAGCTGTATGACATCGCACCGGT & For mdh insertional mutant, reverse, Xbal & This study \\
\hline pr33 & AAAGAGCTCGCGGCGTGAGACTAAGGCATC & For cra insertional mutant, forward, Sacl & This study \\
\hline pr34 & AAATCTAGACAATGGCAAAGCGCAGAAGTA & For cra insertional mutant, reverse, $\mathrm{Xbal}$ & This study \\
\hline vah1 F RT & GTTTGGTATGGAACACCGCTCAAG & For vah1 qRT-PCR, forward & This study \\
\hline vah1 R RT & GGCTCAACCTCTCCTTGTAACCAA & For vah1 qRT-PCR, reverse & This study \\
\hline plp F RT & CAGACGACCACCAGTAACCACTAA & For plp qRT-PCR, forward & [8] \\
\hline plp R RT & GCAATCATGATGACCCAGCAACAG & For plp qRT-PCR, reverse & [8] \\
\hline Pm111 & GGAAATTATTCCGCCGACGATGGA & For rtxA qRT-PCR, forward & [7] \\
\hline Pm112 & GCCGATACCGTATCGTTACCTGAA & For $r t x A$ qRT-PCR, reverse & [7] \\
\hline
\end{tabular}

of each cycle. Samples were run in triplicate along with the no-reverse-transcriptase control and the no-template control. All experiments were repeated at least twice.

\section{Growth experiments}

To cultivate bacteria for growth experiments, $V$. anguillarum cells grown overnight at $27{ }^{\circ} \mathrm{C}$ in LB20 supplemented with the appropriate antibiotics were harvested by centrifugation $(9000 \times g, 2 \mathrm{~min})$, washed twice and resuspended in in NSS. A $200 \mu \mathrm{l}$ aliquot of the $V$. anguillarum NSS suspension was transferred into a 96-well plate with a clear flat bottom and the optical density at $600 \mathrm{~nm}\left(\mathrm{OD}_{600}\right)$ was read by a VersaMax $^{\text {Tn }}$ Absorbance Microplate Reader (Molecular Devices). The $V$. anguillarum NSS suspension was prepared to an $\mathrm{OD}_{600}$ of $0.420\left(\sim 4 \times 10^{7} \mathrm{CFU} / \mathrm{ml}\right)$ and diluted 1:100 into fresh media. Growth was monitored either by measurement of the $\mathrm{OD}_{600}$ or by serial dilution and plate counts.

\section{Resolving the merodiploid in the icd mutant}

$V$. anguillarum icd mutant cells grown in LB20 supplemented with appropriate antibiotics for $19 \mathrm{~h}$ at $27{ }^{\circ} \mathrm{C}$ were harvested by centrifugation $(9000 \times g$, $2 \mathrm{~min}$ ), washed three times in NSS, and resuspended in NSS. Cell suspensions $(100 \mu \mathrm{l})$ were spread onto
Marine Minimum Median $(3 \mathrm{M})+0.15 \%$ glucose agar. Well-isolated colonies were picked and subsequently streak purified onto a new $3 \mathrm{M}+0.15 \%$ glucose agar. Isolated colonies were then transferred to $\mathrm{LB} 20 \mathrm{Cm}^{5}$ agar to screen for chloramphenicol sensitivity. Resolution of the merodiploid was confirmed by PCR amplification.

\section{Statistical analysis}

A Kaplan-Meier survival analysis with log rank significance test was performed on the survival curves in the fish infection experiment. Student's T-tests assuming unequal variances were used for experiments containing two data groups. One-way ANOVA with Tukey post hoc test was performed for all other experiments. $P$ values of $<0.05$ were considered statistically significant.

\section{Results}

Identification and mutant construction of TCA cycle genes in $V$. anguillarum

In order to identify gene targets for mutagenesis the published genomes of $V$. anguillarum strains 775 , 96F, M3, NB10, RV22, 90-11-286 and the $V$. anguillarum M93Sm draft genome (accession number NOWD00000000) annotated by RAST were examined and found to have the following TCA cycle genes/operons: gltA, acnB, icd, sucAB, sucCD, sdhCDAB, 


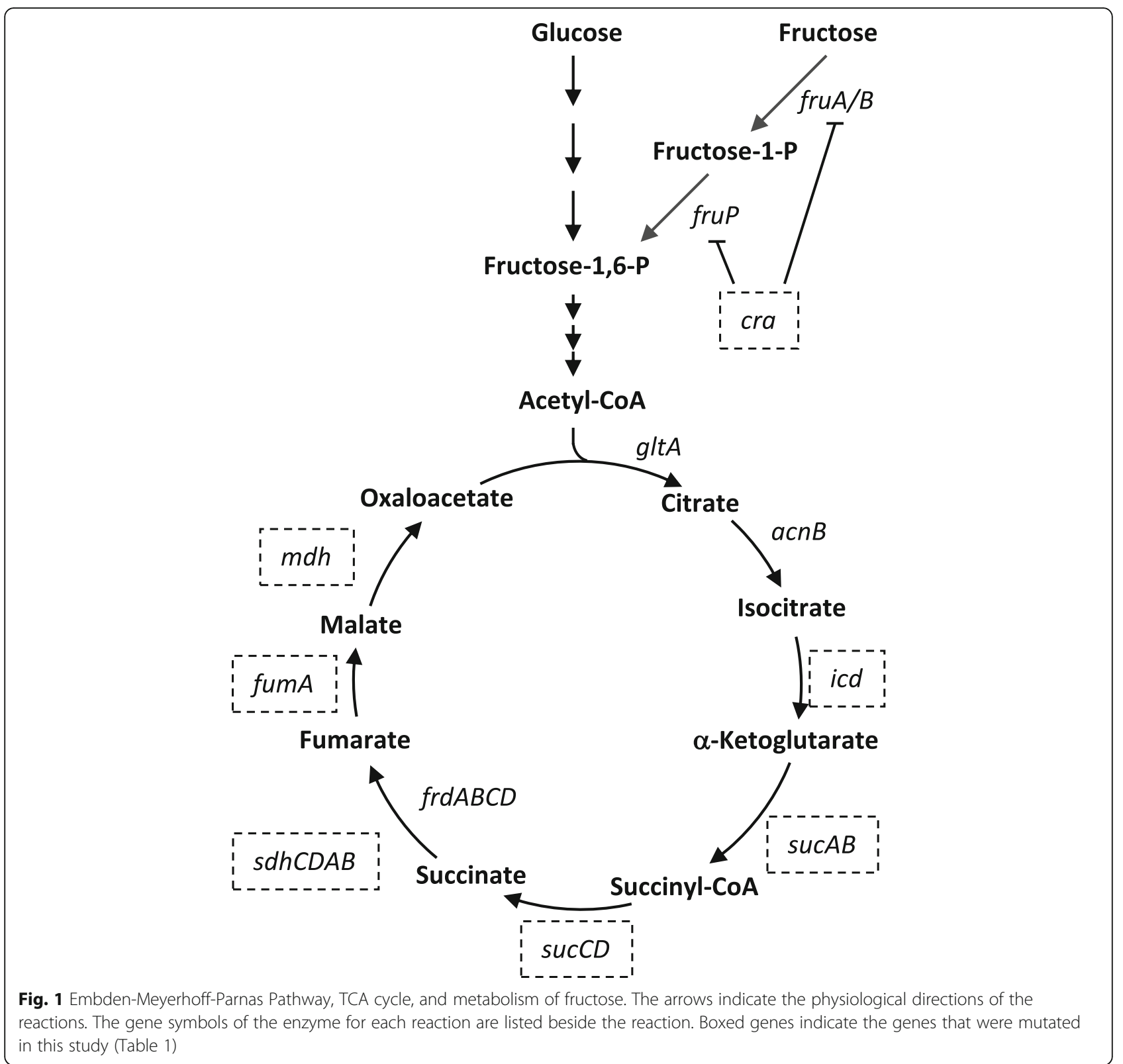

frdABCD fumA, and $m d h$ (Fig. 1 and Table 3). While this set of genes allows for a fully functional TCA cycle, none of the strains have a fumC gene, which encodes the aerobic fumarate class II hydratase. All strains also lack the anaerobic fumarate hydratase (fumB) gene. Additionally, all strains possessed cra, which encodes the repressor of fructose metabolism in S. enterica [22]. The $V$. anguillarum M93Sm sequences for the icd, sucA, sucC, sdhC, fumA, mdh, and cra genes were used to create insertional mutations in $V$. anguillarum M93Sm. The seven mutant strains and the one restored strain listed in Table 1 were constructed using the primers listed in Table 2 as described in the Methods. icd mutant is highly attenuated for virulence against rainbow trout

The virulence of the seven $V$. anguillarum metabolism mutants were tested on rainbow trout and compared to wild type M93Sm in order to determine if mutations in metabolism could affect pathogenesis. Groups of five fish were infected by IP-injection (as described in the Methods) with either the wild type (M93Sm), icd mutant (XM420), sucA mutant (XM440), sucC mutant (XM450), $s d h C$ mutant (XM460), fumA mutant (XM470), $m d h$ mutant (XM410) or cra mutant (XM430) in NSS at a dosage of $\sim 2 \times 10^{5} \mathrm{CFU}$ per fish. Injection with NSS only served as a negative control (Mock). During the 14-day observation window, $40 \%$ of M93Sm infected fish 
Table 3 Metabolism genes examined in this study

\begin{tabular}{|c|c|c|}
\hline $\begin{array}{l}\text { Gene or } \\
\text { operon }\end{array}$ & Product & $\begin{array}{l}\text { Present in sequenced } \\
V . \text { anguillarum strains }^{\text {a }}\end{array}$ \\
\hline gltA & Type II citrate synthase & Yes \\
\hline$a c n B$ & Aconitate hydratase B & Yes \\
\hline icd & Isocitrate dehydrogenase & Yes \\
\hline$S U C A B$ & $\begin{array}{l}\text { 2-oxoglutarate dehydrogenase } \\
\text { (E1 component, E2 component) }\end{array}$ & Yes \\
\hline sucCD & $\begin{array}{l}\text { Succinyl-CoA synthetase } \\
\text { (beta subunit, alpha subunit) }\end{array}$ & Yes \\
\hline$s d h C D A B$ & $\begin{array}{l}\text { Succinate dehydrogenase } \\
\text { (cytochrome b556 subunit, } \\
\text { membrane anchor subunit, } \\
\text { flavoprotein subunit, } \\
\text { iron-sulfur protein) }\end{array}$ & Yes \\
\hline $\operatorname{frd} d A B C D$ & $\begin{array}{l}\text { Fumarate reductase } \\
\text { (flavoprotein subunit, } \\
\text { iron-sulfur subunit, anchor } \\
\text { subunit, anchor subunit) }\end{array}$ & Yes \\
\hline fumAC & $\begin{array}{l}\text { Aerobic fumarate hydratase } \\
\text { (class I, class II) }\end{array}$ & $\begin{array}{l}\text { fumA: Yes; fumC: } \\
\text { not found }\end{array}$ \\
\hline fum $B$ & $\begin{array}{l}\text { Anaerobic fumarate hydratase } \\
\text { (class I) }\end{array}$ & Not found \\
\hline mdh & Malate dehydrogenase & Yes \\
\hline cra & Fructose repressor protein & Yes \\
\hline
\end{tabular}

${ }^{a}$ V. anguillarum strains: M93Sm, 775, 96F, M3, NB10, RV22, 90-11-286

survived. Fish infected with the $s u c A$ mutant, $s d h C$ mutant or icd mutant had a higher survival percentage than M93Sm (50\% for sucA mutant, $80 \%$ for $s d h C$ mutant, and $100 \%$ for icd mutant); however, only the difference between the icd mutant and M93Sm was statistically significant $(p=0.037)$ (Fig. 2a). The experiment was repeated using a two-fold higher dose $\left(\sim 4 \times 10^{5} \mathrm{CFU}\right.$ per fish) of M93Sm and the three mutant strains (icd mutant, sucA mutant and $s d h C$ mutant) that exhibited attenuated virulence in the previous experiment. At this dose, only $20 \%$ of M93Sm-infected fish survived. Only the icd mutant-infected fish had a statically significant higher survival percentage (100\%) compared to M93Sm $(p=0.0153)$ (Fig. 2b). The data indicate the icd mutant is avirulent in these experimental conditions.

Further, we tested the virulence of M93Sm and the icd mutant by another infection route. Groups of 10 fish were infected by immersion as described in the Methods with M93Sm or icd mutant in $1.5 \%$ salt solution at a dose of $\sim 4 \times 10^{6} \mathrm{CFU} / \mathrm{ml}$, or just immersed in a $1.5 \%$ salt solution without $V$. anguillarum as a negative control (Mock). During the 14-day observation window, there was a statistically significant difference $(p=0.007)$ between the survival of M93Sm infected fish (30\%) and icd mutant infected fish (90\%) (Fig. 3). Taken together, the IP infection data and the immersion infection data demonstrate that the icd mutant is highly attenuated for infection in rainbow trout.

Pre-treatment by immersion with the icd mutant protected rainbow trout from the subsequent challenge of $V$. anguillarum M93Sm

Fish previously challenged by immersion with the icd mutant were subsequently challenged with the wild type M93Sm strain to test if the icd mutant was immunogenic. Six weeks after the initial infection, a group of five fish that survived the initial infection with the icd mutant (labeled as "treated with the icd mutant" in Fig. 4) and a group of five "untreated" fish were infected via immersion with $\mathrm{M} 93 \mathrm{Sm}$ at a dose of $\sim 4 \times 10^{6} \mathrm{CFU} / \mathrm{ml}$ and were observed for 14 days. By day 2 all fish in the untreated group died. All fish in the group treated with the icd mutant survived the 14-day observation period. The difference between the two experimental groups was statistically significant $(p=0.008)$. The results indicate that the icd mutant is immunogenic and protective against wild type infection when administered by immersion.

\section{All mutants exhibited either same or higher expression levels of the three hemolysin genes compared to wild type}

Vah1, RtxA, and Plp are the three hemolysins found in M93Sm and are responsible for the hemolytic/cytolytic activity against fish erythrocytes, leukocyte and epithelial cells $[7,9,11]$ and unpublished data]. We tested the expression of $v a h 1, r t x A$ and plp during exponential phase to determine whether mutations in metabolism could affect the expression of these hemolysin genes. Data indicate that in all mutants except the icd mutant, expression of vah1 and plp were up regulated by 1.49-16.15-fold compared to M93Sm with most of the changes being significant (Fig. 5). In the icd mutant, expression of $p l p$ was up regulated by 1.76 -fold while the expression of vah1 was slightly decreased (to $49 \%$ of WT), neither of which was a significant change from M93Sm (Fig. 5). Plp is the most efficient hemolysin against fish erythrocytes [11]. TCA cycle mutants with an increased expression of $p l p$ also demonstrated an increased zone of hemolysis on $5 \%$ fish blood agar plates (Additional file 1: Figure S1). There was no change in the zone of hemolysis for the icd mutant. Expression of $r t x A$ in all mutants was not significantly different from M93Sm (Fig. 5). Taken together, all metabolism mutants have the same or higher expression levels of hemolysin genes compared to the wild type. 

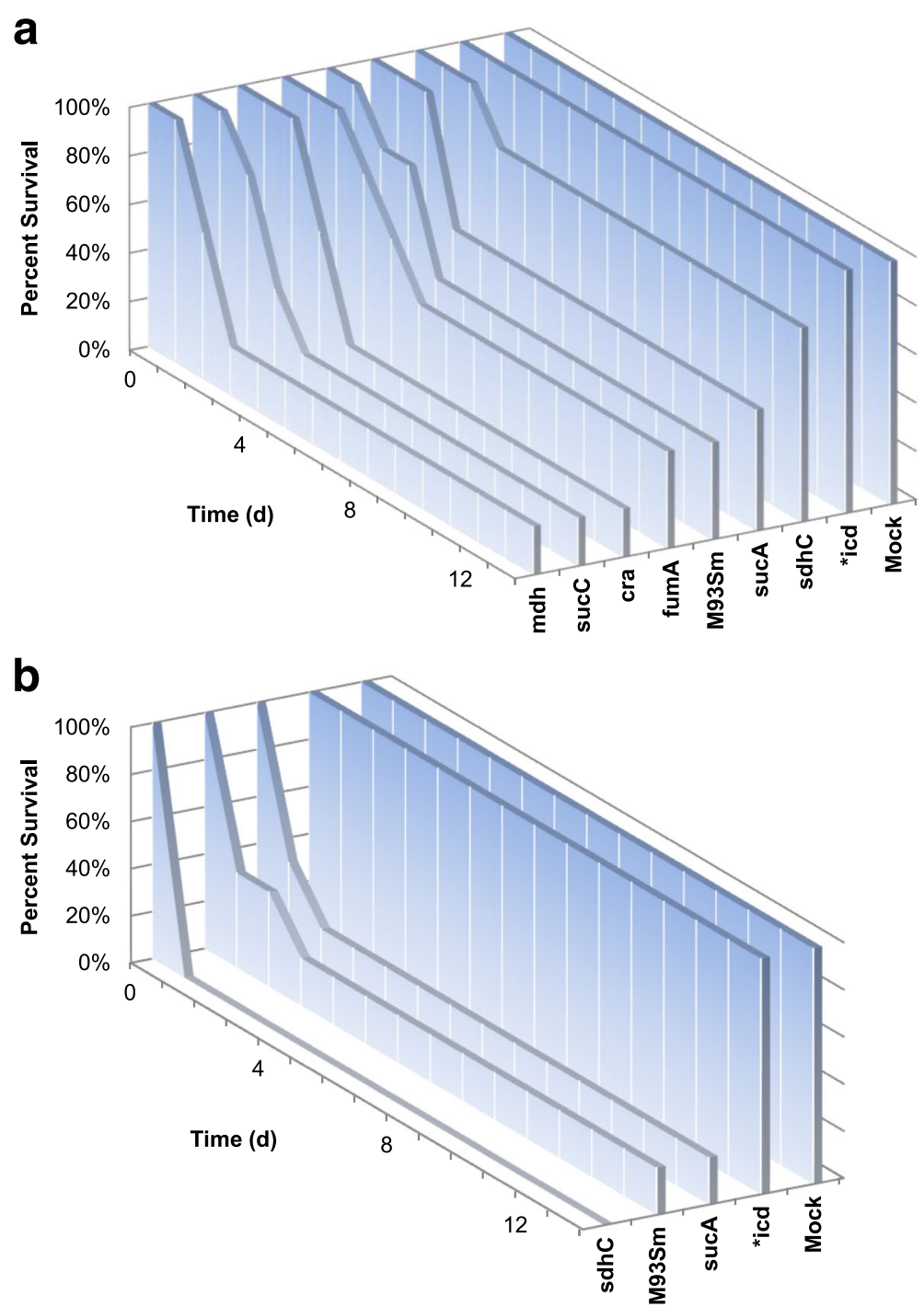

Fig. 2 Percent survival of rainbow trout IP injected with $V$. anguillarum wild type (M93Sm) and various mutant strains at a dosage of a $2 \times 10^{5}$ CFU/fish and $\mathbf{b} 4 \times 10^{5}$ CFU/fish. Negative control groups of fish (Mock) were injected with sterile NSS. Five fish were used for each treatment. (One fish treated with the sucA mutant died, but not from vibriosis and no $\mathrm{V}$. anguillarum were recovered, so only four fish were counted).

*Statistically significant difference compared to M93Sm $(p<0.05)$

\section{icd mutant exhibited significant lower cell density limit than wild type in two forms of rich media}

Figure 6 shows the typical growth curves for the wild type $V$. anguillarum M93Sm and the seven metabolism mutants in LB20 broth. In these growth conditions, M93Sm, the icd mutant, and the cra mutant exhibited classic bacterial growth curves with a lag phase, an exponential phase and a stationary phase. The $s u c A$, sucC, sdhC, fumA and $m d h$ mutants all exhibited a two-stage growth curve, with each stage consisting of a lag phase and an exponential phase. The exponential phase in the first growth stage was named exponential phase I and the exponential phase in the second growth stage was named exponential phase II.
The generation times of the exponential phases of all mutants were longer than for M93Sm (Table 4). The final cell density (measured by $\mathrm{OD}_{600}$ ) of the icd mutant after $23 \mathrm{~h}$ was the lowest among all strains. Similarly, after $24 \mathrm{~h}$ of growth in LB20 the final cell density (CFU/ml) of the icd mutant was $47 \%$ that of M93Sm (Table 5) and the difference is significant $(p=0.011)$. M93Sm and the icd mutant were grown in NSS supplemented with $200 \mu \mathrm{g}$ protein/ml of fish gastrointestinal mucus (NSSM) to better replicate conditions within a host. After $24 \mathrm{~h}$ of growth in NSSM the final cell density of the icd mutant was only $\sim 31 \%$ of that for M93Sm (Table 5) and the difference is significant $(p=0.007)$. 


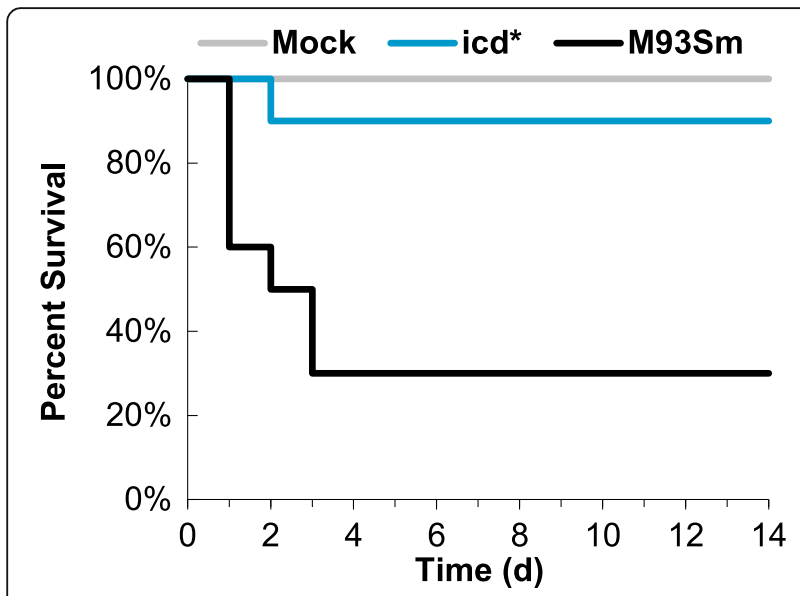

Fig. 3 Percent survival of rainbow trout infected by immersion with $V$. anguillarum strains M93Sm (wild type) or XM420 (icd) at a dose of $4 \times 10^{6} \mathrm{CFU} / \mathrm{ml}$. A negative control group of fish (Mock) was immersed in sterile NSS. Ten fish were used for each treatment. *Statistically significant difference compared to M93Sm $(p<0.05)$

\section{Growth in LB20 supplemented with $118 \mathrm{mM}$ glutamate} restores growth of the icd mutant to wild type levels The icd mutant is unable convert isocitrate into $\alpha$ ketoglutarate, the immediate precursor of glutamate. Consequently, the icd mutant was only able to grow in $3 \mathrm{M}+0.15 \%$ glucose with the addition of glutamate (Fig. 7a). Glutamate was added to LB20 to determine if the icd mutant final cell density would increase. Figure $7 \mathrm{~b}$ shows the typical growth curves of M93Sm and the icd mutant in LB20 with (solid lines) and without (dashed lines) the addition of $118 \mathrm{mM}$ of glutamate. After $24 \mathrm{~h}, \mathrm{M} 93 \mathrm{Sm}$ and the icd mutant grew to similar final cell densities when LB20 was supplemented with $118 \mathrm{mM}$ glutamate. Additionally, Fig. 7c demonstrate

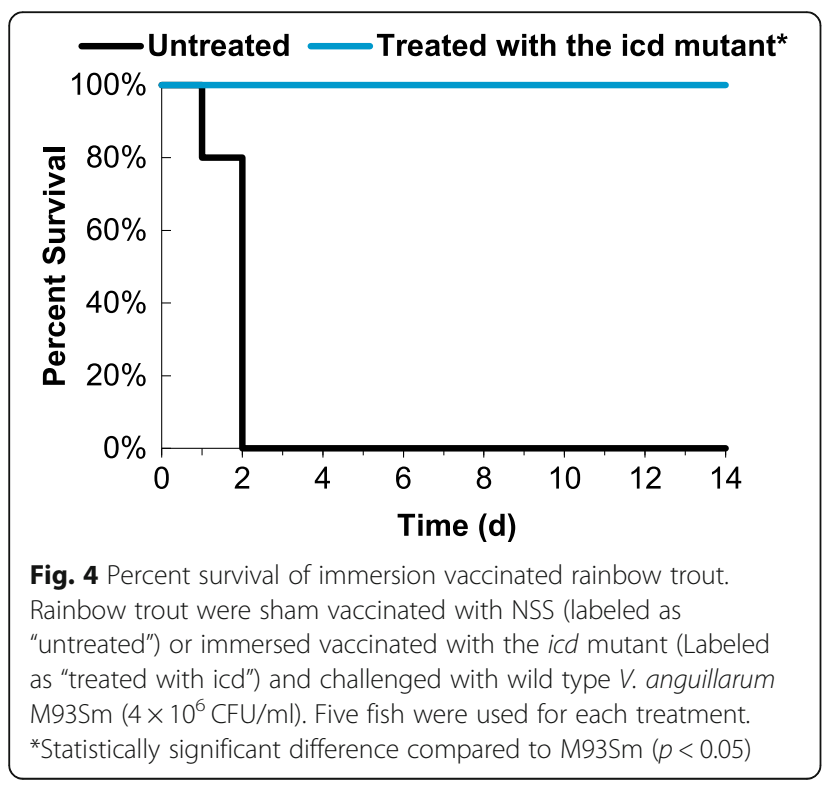

that decreasing the amount of glutamate (from $118 \mathrm{mM}$ to $2.95 \mathrm{mM}$ ) added to LB20 decreases the final cell density of the icd mutant, but not M93Sm, after $24 \mathrm{~h}$ of growth. The final cell density of the icd mutant was not restored to a wild type level when LB20 was supplemented with glucose, succinate (Additional file 2: Figure S2) or gluconate (Fig. 7c).

\section{Resolving the merodiploid in the icd mutant restores growth and pathogenicity}

A revertant to the wild type icd gene was selected to demonstrate that the icd mutant (XM420, a merodiploid with an insertion in the icd gene) contained no additional mutations that could be causing the loss of pathogenicity and decreased cell density. Initially, attempts were made to complement the icd mutant in trans by cloning icd and its native promoter into the pSUP203 vector; however, all pSUP203-icd vectors isolated from E. coli SM10 contained single nucleotide substitutions that resulted in amino acid changes in icd that inactivated isocitrate dehydrogenase (data not shown). Since the icd mutant is unable to grow on $3 \mathrm{M}$ + glucose, icd mutants that spontaneously resolved the merodiploid were isolated on $3 \mathrm{M}+$ glucose agar plates as described in the Methods. The reversion rate of the icd mutant to a wild type phenotype grown in LB20 overnight was calculated to be 1 out of $1.6 \times 10^{10}$ cells. Additional file 3: Figure S3 shows the typical growth curves for M93Sm, the icd mutant and the restored icd strain in LB20 and $3 \mathrm{M}+0.15 \%$ glucose. M93Sm and the restored icd strain were able to grow in $3 \mathrm{M}+0.15 \%$ glucose unlike the icd mutant (Additional file 3: Figure S3A). Additionally, when the strains were grown in LB20 the final cell density returned to wild type levels when icd was restored (Additional file 3: Figure S3B). To determine if restoring icd restores pathogenicity, juvenile rainbow trout were challenged via immersion with M93Sm, the icd mutant and the restored icd strain at a dose of between $4 \times$ $10^{6}$ and $8 \times 10^{6} \mathrm{CFU} / \mathrm{ml}$. After day 8, 26\% (5/19) of the M93Sm challenged fish, $40 \%(6 / 15)$ of the restored icd challenged fish and 95\% (19/20) of the icd mutant challenged fish survived (Fig. 8). There was no statistically significant difference between M93Sm and the restored icd strain $(p=0.50)$. Again, there was a statistically significant difference between M93Sm and the icd mutant $(p<$ $0.00004)$. The results indicate that when the merodiploid present in the icd mutant is resolved, wild type levels of growth in $3 \mathrm{M}+0.15 \%$ glucose and LB20 and pathogenicity against juvenile rainbow trout is returned.

\section{Discussion}

The tricarboxylic acid (TCA) cycle is involved in the generation of energy through the oxidation of acetate. TCA intermediates serve as precursor metabolites for 


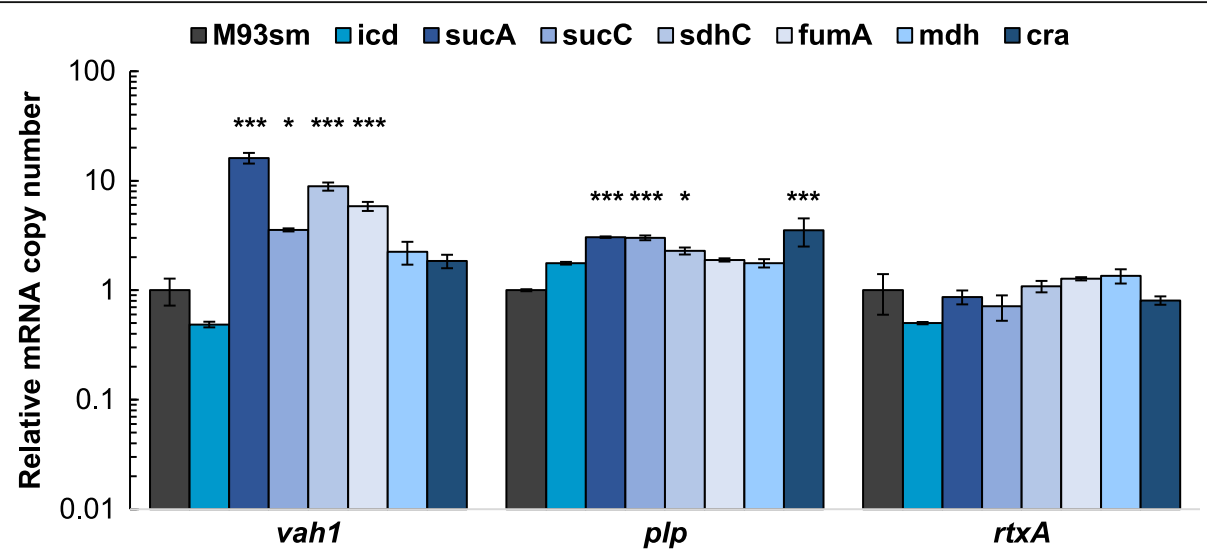

Fig. 5 Relative expression of vah1, plp, rtxA determined by qRT-PCR analysis of $V$. anguillarum wild-type (M93Sm) and various TCA mutants during logarithmic (Log)-phase growth. The data presented are representative of two independent experiments. Each value is the average for three replicates. Between marked strains and M93Sm: ${ }^{*} p<0.05$ and ${ }^{* * *} p<0.001$. Error bars represent 1 standard deviation

the synthesis of amino acids and peptidoglycan. The M93Sm genome along with the published genomes of $V$. anguillarum strains 775, 96F, M3, NB10, RV22, 90-11286 were examined for TCA cycle enzymes and the following genes were found: gltA, acnB, icd, sucAB, sucCD, sdhCDAB, frdABCD, fumA, and $m d h$ (Fig. 1 and Table 3). Additionally, cra, which encodes the repressor of fructose metabolism in S. enterica and E. coli and has previously been shown to be essential for $S$. enterica virulence, is present in the $V$. anguillarum genomes [22].

When in a nutrient limited environment, bacteria must be able to synthesize any essential metabolites that are not freely available in order to grow. Previous studies have shown that mutations in central metabolism genes result in attenuation of virulence in several intracellular pathogens including S. enterica, uropathogenic E. coli (UPEC), M. tuberculosis and E. ictaluri [17-19, 21, 2326]. These observations suggest that central metabolism is necessary for these intracellular pathogens to function inside the nutrient-limited environment of the phagosome; however, $V$. anguillarum is not an intracellular pathogen. While some studies have suggested that $V$. anguillarum can survive internally in fish epithelial cells and CHSE cells (derived from pooled embryonic cells from Oncorhynchus tshawytscha), more recent studies have demonstrated that $V$. anguillarum actively evades phagocytosis by fish epithelial cells and cannot survive for $24 \mathrm{~h}$ in macrophages [35-38]. In this study, fish were infected with $V$. anguillarum strains by either of two methods: intraperitoneal injection or immersion with both methods resulting in a similar percent survival when fish were challenged with M93Sm (20\% for injection, see Fig. 2a and b; 0\% 30\% for immersion, see Fig. 3). Only the icd mutant had a statistically significant higher level of survival compared to the wild type, 100\% for IP injection (Fig. 2a and b) and 90\% for immersion (Fig. 3). It is not thought that reversion of the merodiploid to a wild type phenotype caused the other

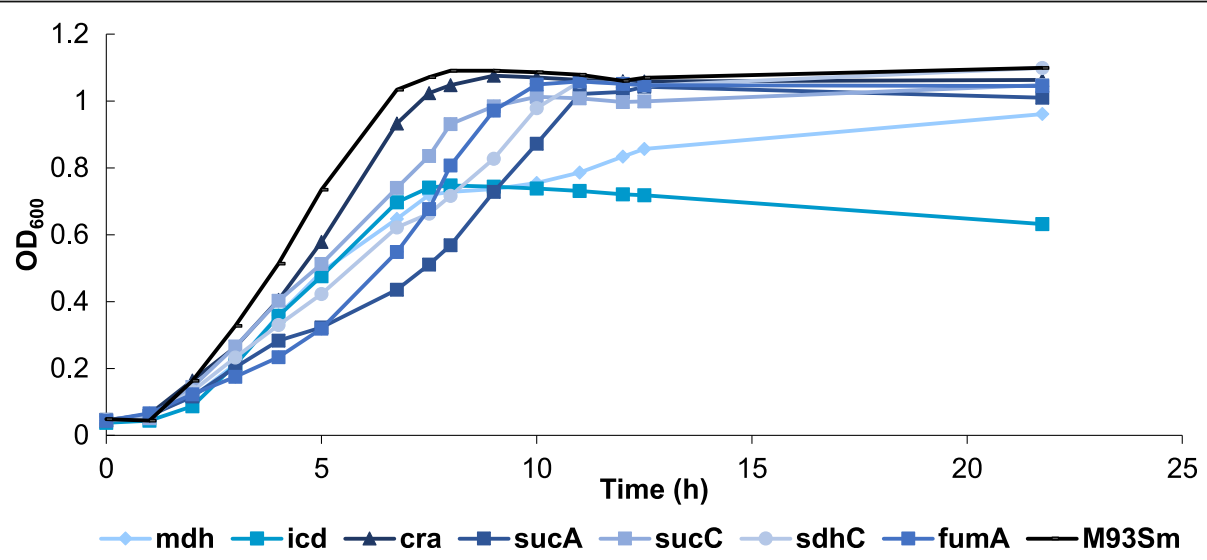

Fig. 6 Growth curves of various $V$. anguillarum strains grown in LB20 at $27{ }^{\circ} \mathrm{C}$ with shaking (200 rpm). At various time points after inoculation samples were taken for determination of optical density at $600 \mathrm{~nm}\left(\mathrm{OD}_{600}\right)$. The data are from one representative experiment 
Table 4 Generation times of various $V$. anguillarum strains grown in LB20

\begin{tabular}{|c|c|c|}
\hline Strain & $\begin{array}{l}\text { Exponential Phase I } \\
\text { (Minutes) }\end{array}$ & $\begin{array}{l}\text { Exponential Phase II } \\
\text { (Minutes) }\end{array}$ \\
\hline M93Sm & 44.00 & NA \\
\hline icd & 54.95 & NA \\
\hline SUCA & 64.32 & 98.52 \\
\hline sucC & 52.42 & 99.57 \\
\hline$s d h C$ & 61.19 & 101.70 \\
\hline fumA & 73.55 & 89.38 \\
\hline mdh & 67.11 & 115.28 \\
\hline $\mathrm{cra}$ & 58.59 & NA \\
\hline
\end{tabular}

NA not applicable

${ }^{a}$ Values calculated from data presented in Fig. 6 during exponential growth

metabolism mutants to be virulent because chloramphenicol resistant colonies were isolated from the organs of dead fish. IP injection bypasses the need for invasion. No mortalities resulted from IP injection with the icd mutant indicating that icd is required for $V$. anguillarum persistence and growth in fish tissues. Rainbow trout infected with the icd mutant via immersion and subsequently challenged with the M93Sm wild type showed $100 \%$ survival (Fig. 4) demonstrating that the icd mutant had immunoprotective effects and elicited an adaptive immune response. Moreover, as a proof of concept, the data suggest that an icd deletion mutant could be the basis for a live attenuated vaccine against $V$. anguillarum infection.

Our observation that a knockout of the icd gene results in attenuation of virulence raises the question of whether expression of required virulence genes is significantly reduced in the mutant and, therefore, results in attenuation. We previously identified and characterized three hemolysin/cytolysin genes and their encoded proteins secreted by $V$. anguillarum: plp, vah1 and $r t x A$ [7, 9,11 . While mutations in plp and vah1 have modest effects on virulence against fish epithelial cells and fish, a knockout mutation in $r t x A$ is avirulent in fish $[7,9,11]$. All metabolism mutants exhibited no significant declines in the expression of three hemolysins (Fig. 5) and most of the mutants exhibited increased expression. Accordingly, the icd mutant is not attenuated by the lack of hemolysin production because the decrease in $r t x A$ and vah1 expression was not significant; however, future studies could examine the expression of other virulence

Table 5 Final cell density (CFU/ml) of various $V$. anguillarum cultures grown for $24 \mathrm{~h}$

\begin{tabular}{lll}
\hline Strain & CFU/ml in LB20 & CFU/ml in NSSM $(200 \mu \mathrm{g} / \mathrm{ml})$ \\
\hline M93Sm & $3.4 \times 10^{9}\left( \pm 0.3 \times 10^{9}\right)$ & $4.2 \times 10^{9}\left( \pm 0.7 \times 10^{9}\right)$ \\
icd & $1.6 \times 10^{9}\left( \pm 0.02 \times 10^{9}\right)^{*}$ & $1.3 \times 10^{9}\left( \pm 0.3 \times 10^{9}\right)^{*}$ \\
\hline
\end{tabular}

*Statistically significant difference compared to M93Sm $(p<0.05)$ factors. It is unclear why expression of $p l p$ and $v a h 1$ is increased in the metabolism mutants. Minato et al. [39] demonstrated the accumulation of acetyl-CoA in Vibrio cholerae central metabolism mutants resulted in an increased expression of its virulence gene activator ToxT. It is possible that accumulation or depletion of certain metabolites in $V$. anguillarum could increase hemolysin/ cytolysin expression. Expression of $h l y U$, the positive regulator of the both the vah1 plp gene cluster and the $r t x A$ gene cluster, was examined and shown to be upregulated in the sucA and $m d h$ mutants (data not shown) [40]. However, the increased expression of $h l y U$ may not be the sole explanation for the increased expression of $p l p$ and vah1 because an increase in expression of $r t x A$ should have also occurred.

The growth rate and final cell density was determined for all metabolism mutants grown in LB20 for $24 \mathrm{~h}$. The slowest growing mutant, fumA, was as virulent as the wild type while the mutant with the lowest final cell density, icd, was attenuated suggesting that decreased final cell density results in a loss of pathogenicity against rainbow trout (Figs. 2, 6, Tables 4 and 5). When the mutation in icd was resolved, the restored icd strain demonstrated the wild type phenotype for both growth and pathogenicity (Additional file 3: Figure S3A and B and Fig. 8). While it is possible that the insertional mutation affected the expression of the two genes flanking icd (ribosomal large subunit pseudouridine synthase E (Accession number: WP_017043910.1) and cold shock domain protein CspD (Accession number: WP_013857087.1)), it is unlikely as neither gene is part of an operon that includes $i c d$. Since isocitrate dehydrogenase catalyzes the formation of $\alpha$-ketoglutarate (the immediate precursor of glutamate) from isocitrate, the icd mutant is auxotrophic for glutamate (Fig. 7a). Our data demonstrate that the icd mutant stops growing once exogenous glutamate or its derivatives are exhausted (Fig. $7 \mathrm{~b}$ and c). The data also demonstrate the decreased growth yield was not do to a reduction of ATP production as addition of gluconate or succinate did not restore growth to a wild type cell density. It is interesting that the only other auxotrophic mutant, $s u c A$, grows to a wild type cell density in LB20 and is as virulent as the wild type considering it cannot synthesize succinyl-CoA, a metabolite needed for the synthesis of lysine, methionine and diaminopimelic acid. Presumably, succinyl-CoA or its derivatives are not limiting in LB20 or in fish tissues. Furthermore, this also suggests that the icd mutant is primarily starved for glutamate and would not need to synthesize succinyl-CoA by metabolizing glutamate to $\alpha$-ketoglutarate. We hypothesize that during infection the icd mutant is unable to obtain enough $\alpha$-ketoglutarate derivatives to grow to a wild type cell density and, therefore, cannot reach a cell 


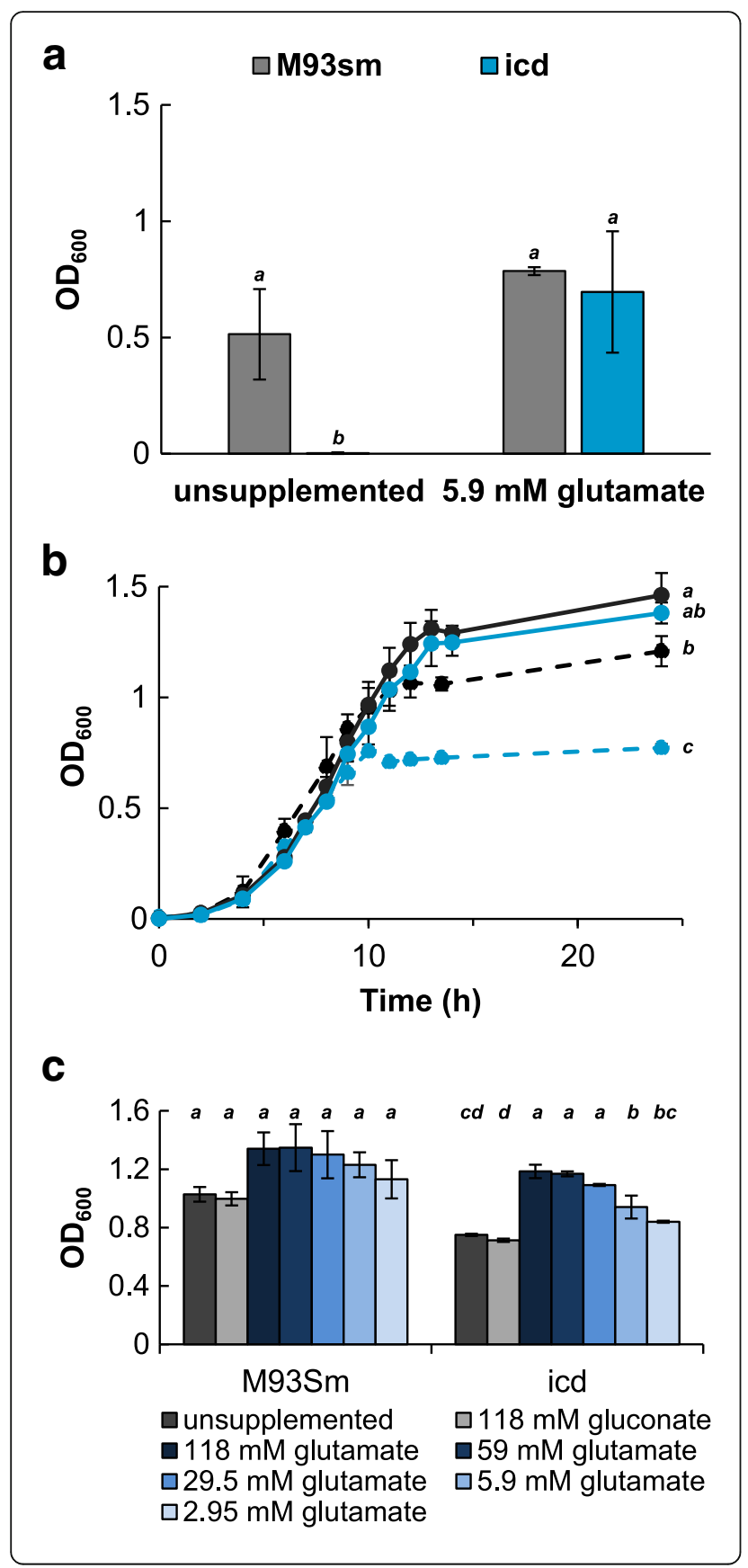

Fig. 7 Growth of $V$. anguillarum WT (M93Sm) and the icd mutant under various conditions. a Final cell densities $\left(\mathrm{OD}_{600}\right)$ of $V$. anguillarum strains after $24 \mathrm{~h}$ of growth in $3 \mathrm{M}$ plus $0.15 \%$ glucose supplemented with or without $5.9 \mathrm{mM}$ glutamate. b Growth curves of $V$. anguillarum M93Sm (black) and the icd mutant (blue) in LB20 (dashed lines) or LB20 supplemented with $118 \mathrm{mM}$ glutamate (solid lines). Statistical analysis was based on data at $24 \mathrm{~h}$. c Final cell densities $\left(\mathrm{OD}_{600}\right)$ of $V$. anguillarum M93Sm and icd mutant strains grown in LB20 supplemented with decreasing amounts of glutamate. In each experiment cells grown overnight in LB20 were washed in NSS and used to inoculate the appropriate media. Cultures were incubated at $27{ }^{\circ} \mathrm{C}$ in a shaking water bath (200 rpm) and at various time points after inoculation samples were taken for determination of optical density at $600 \mathrm{~nm}\left(\mathrm{OD}_{600}\right)$. Different letters indicate statistical significance among groups $(p<0.05)$. Error bars represent 1 standard deviation

density necessary for a successful systemic infection. In support, it has previously been demonstrated that a $V$. anguillarum M93Sm mugA mutant that was unable to grow in salmon intestinal mucus was avirulent against Atlantic salmon [41]. Additionally, when $V$. anguillarum 775 was cured of its plasmid-encoded siderophore, the mutant was unable to sequester iron and exhibited decreased virulence [42, 43].

M93Sm is an O2 $\alpha$ serotype and the presumed infection route is through the gastrointestinal tract as no necrotic skin lesions have ever been observed with this strain (unpublished data). The in vitro growth experiment (Table 5) suggests that there are not enough $\alpha$ ketoglutarate derivatives in intestinal mucus to support the growth of the $i c d$ mutant to a wild type cell density even though it is the metabolite with the second highest concentration $(3.03 \mathrm{mM})$ in rainbow trout mucus [44]. It should be noted that for in vitro growth experiments

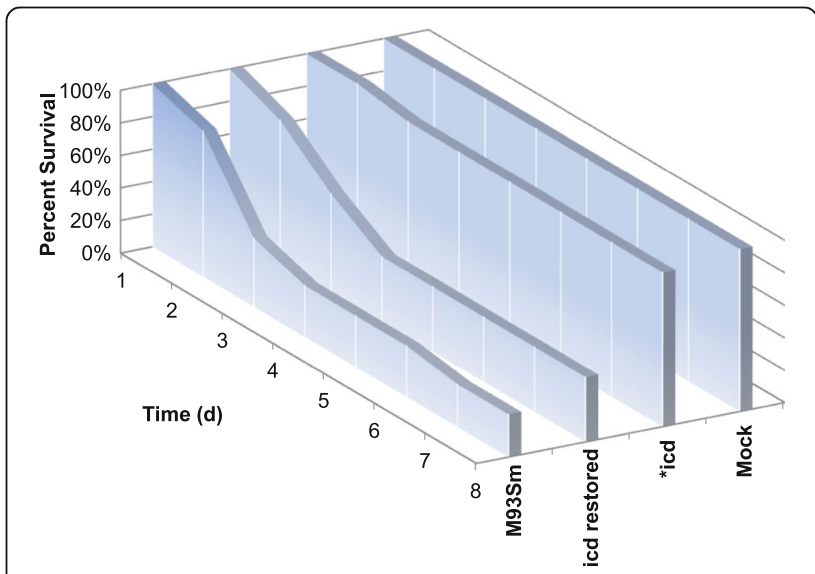

Fig. 8 Percent survival of rainbow trout immersed with various $V$. anguillarum strains at a dosage of $4 \times 10^{6}$ to $7 \times 10^{6} \mathrm{CFU} / \mathrm{ml}$. Five fish were used for the uninfected (mock) group. Fifteen fish were treated with the restored icd strain. Nineteen fish were treated with M93Sm and twenty fish were treated with the icd mutant. *Statistically significant difference compared to M93Sm $(p<0.01)$ 
the concentrations of glutamate and glutamine in the mucus are not known and the growth conditions represent an ideal environment for growth; $V$. anguillarum does not have to evade the fish immune system or compete with commensal bacteria and it is not expected that the icd mutant will grow to the cell density shown in the in vitro growth experiments in the fish. As demonstrated by Muroga et al., [45] $V$. anguillarum found in the spleen and intestine of moribund fish challenged via immersion only reached a cell density of $4.0 \times 10^{8} \mathrm{CFU} / \mathrm{g}$ and $2.5 \times 10^{7} \mathrm{CFU} / \mathrm{g}$ respectively. Altinok et al. [46] showed a $V$. anguillarum succinate dehydrogenase mutant was avirulent against rainbow trout when injected at a dose at $10^{5} \mathrm{CFU}$. Similar to our results, the authors showed that the succinate dehydrogenase mutant grew to a cell density slightly lower than the wild type at $12 \mathrm{~h}$; however, the authors failed to show the growth yield at $24 \mathrm{~h}$. Further, the authors did not create a complement strain to demonstrate that the loss of virulence was solely do to mutating $s d h B$. Most importantly, the ATCC has redesignated their strain as a Pseudomonas species.

\section{Conclusions}

Seven $V$. anguillarum metabolism mutants were created and examined for pathogenicity against juvenile rainbow trout, hemolysin/cytolysin expression and growth in rich media. Of the central metabolism mutants, only the icd mutant showed strong attenuation in virulence, which did not result from a decrease in virulence factor expression. In addition, only the icd mutant had a final cell density that was lower than the wild type, which resulted from the inability to synthesize $\alpha$-ketoglutarate and downstream metabolites. Taken together, the data suggest that during infection, if $V$. anguillarum is unable to synthesize essential molecules (e.g. $\alpha$-ketoglutarate/2-oxoglutarate) and when those molecules or their derivatives (e.g. glutamate, glutamine) become limiting in the host, $V$. anguillarum will be unable to grow to a density necessary to sustain a systemic infection of the host.

\section{Additional files}

Additional file 1: Figure S1. Hemolytic activity of various $V$. anguillarum strains grown on fish blood agar. Colonies grown overnight on LB20 plates were tooth picked onto LB20 $+5 \%$ trout blood agar plates. The diameter of the zones of hemolysis were measured after $7 \mathrm{~h}$ and $23 \mathrm{~h}$ of growth at $27^{\circ}$ C. Between marked strains and M93Sm: ${ }^{*} p<0.05$ and ${ }^{* *} p<0.01$. Error bars represent 1 standard deviation (PDF $146 \mathrm{~kb}$ )

Additional file 2: Figure S2. Final cell densities $\left(\mathrm{OD}_{600}\right)$ of $\mathrm{V}$. anguillarum WT (M93Sm) and the icd mutant after $24 \mathrm{~h}$ of growth in LB20 supplemented with or without $118 \mathrm{mM}$ glucose and $118 \mathrm{mM}$ succinate. Error bars represent 1 standard deviation (PDF $145 \mathrm{~kb}$ )
Additional file 3: Figure S3. Growth curves of $V$. anguillarum strains M93Sm (WT), the icd mutant and the restored icd strain grown in A) $3 \mathrm{M}$ $+0.15 \%$ glucose and B) LB20. In each experiment cells grown overnight in LB20 at $27{ }^{\circ} \mathrm{C}$ were washed in NSS and used to inoculate the appropriate media. Cultures were incubated at $27^{\circ} \mathrm{C}$ in a shaking water bath (200 rpm) and at various times after inoculation, samples were taken for determination of optical density at $600 \mathrm{~nm}\left(\mathrm{OD}_{600}\right)$. Different letters indicate statistical significance among groups $(p<0.05)$. Statistical analysis was based on data of stationary phase cultures (>12 h) (PDF $142 \mathrm{~kb}$ )

\section{Abbreviations}

3M: Marine Minimum Median; acnB: Aconitate hydratase B; ANOVA: Analysis of variance; ATCC: American Type Culture Collection; ATP: Adenosine triphosphate; CFU: Colony Forming Unit; CHSE: Chinook salmon embryo; Cm: Chloramphenicol; cra: functional fructose repressor; CspD: Cold Shock Domain Protein; DNA: Deoxyribonucleic acid; frdABCD: Fumarate reductase (flavoprotein subunit, iron-sulfur subunit, anchor subunit, anchor subunit); fumAC: Aerobic fumarate hydratase (class I, class II); fumB: Anaerobic fumarate hydratase (class I); gltA: Type II citrate synthase; HlyA: Hemolysin A; HlyU: Positive transcriptional regulator of the plp/vah1 and the rtx gene clusters; H-NS: Histone-like Nucleoid-structuring; IACUC: The Institutional Animal Care and Use Committee; icd: isocitrate dehydrogenase; IP: intraperitoneal injection; Km: kanamycin; LB: Lysogeny broth; LB20: Lysogeny broth containing 2\% NaCl; MARTX: Multifunctional Autoprocessing Repeats-in-Toxin; mdh: Malate dehydrogenase; mugA: mucus utilization gene A; NCBI: National Center for Biotechnology Information; NSS: Nine Salts Solution; NSSM: NSS supplemented with fish gastrointestinal mucus; PCR: Polymerase chain reaction; Plp: Phospholipase; qRT-PCR: RealTime Quantitative Polymerase Chain Reaction; RAST: Rapid Annotation using Subsystem Technology; RNA: Ribonucleic Acid; RtxA: Repeat-in-toxin A; sdhCDAB: Succinate dehydrogenase (cytochrome b556 subunit, membrane anchor subunit, flavoprotein subunit, iron-sulfur protein); Sm: Streptomycin; suCAB: 2-oxoglutarate dehydrogenase (E1 component, E2 component); sucCD: Succinyl-CoA synthetase (beta subunit, alpha subunit); TCA: Tricarboxylic acid; UPEC: uropathogenic Escherichia coll; Vah1: Vibrio anguillarum hemolysin 1

\section{Acknowledgements}

All DNA sequencing and qRT-PCR analyses were conducted at a Rhode Island NSF EPSCOR research facility, the Genomics and Sequencing Center, supported in part by the National Science Foundation EPSCoR Cooperative Agreement \#EPS-1004057.

\section{Funding}

This work was funded by a grant from the USDA-NIFA-AFRI (grant number 2016-67016-24,905). The funding body had no role in the design of the experiments or the interpretation of the data.

\section{Availability of data and materials}

All datasets are presented in this manuscript. Bacterial strains and plasmids are available from the corresponding author upon reasonable request.

\section{Authors' contributions}

Conceived and designed the experiments: XM, EJS, DRN. Performed the experiments: XM, EJS, SLH. Analyzed the data: XM, EJS, DRN. Wrote the paper: XM, EJS, DRN. All authors have read and approved the final version of the manuscript.

\section{Ethics approval and consent to participate}

All animal procedures were conducted according to the guidelines and with the approval of the University of Rhode Island Institutional Animal Care and Use Committee (Reference number AN06-08-002).

\section{Consent for publication}

Not applicable.

\section{Competing interests}

The authors declare that they have no competing interests. 


\section{Publisher's Note}

Springer Nature remains neutral with regard to jurisdictional claims in published maps and institutional affiliations.

\section{Author details}

'Department of Cell and Molecular Biology, University of Rhode Island, Kingston, RI 02881, USA. '2Present Address: Division of Infectious Diseases, Massachusetts General Hospital, 65 Landsdowne St, Cambridge, MA 02139, USA.

Received: 31 July 2017 Accepted: 2 November 2017 Published online: 14 November 2017

\section{References}

1. FAO. The state of world fisheries and aquaculture 2016. Contributing to food security and nutrition for all. FAO: Rome; 2016. p. 200.

2. Frans I, Michiels CW, Bossier P, Willems KA, Lievens B, Rediers H. Vibrio anguillarum as a fish pathogen: virulence factors, diagnosis and prevention. J Fish Dis. 2011;34(9):643-61. https://doi.org/10.1111/j.1365-2761.2011.01279.

3. Austin B, Austin DA. Bacterial fish pathogens: disease of farmed and wild fish. 5th ed. New York, NY: Springer; 2012.

4. O'Toole R, Von Hofsten J, Rosqvist R, Olsson PE, Wolf-Watz H. Visualisation of zebrafish infection by GFP-labelled Vibrio anguillarum. Microbial Pathog. 2004;37(1):41-6. https://doi.org/10.1016/j.micpath.2004.03.001.

5. Spanggaard B, Huber I, Nielsen J, Nielsen T, Gram L. Proliferation and location of Vibrio anguillarum during infection of rainbow trout, Oncorhynchus mykiss (Walbaum). J Fish Dis. 2000;23(6):423-7. https://doi.org/ 10.1046/j.1365-2761.2000.00257.x

6. Denkin SM, Nelson DR. Regulation of Vibrio anguillarum empA metalloprotease expression and its role in virulence. Appl Environ Microbiol. 2004;70(7):4193-204. https://doi.org/10.1128/AEM.70.7.4193-4204.2004

7. Li L, Rock JL, Nelson DR. Identification and characterization of a repeat-intoxin gene cluster in Vibrio anguillarum. Infect Immun. 2008;76(6):2620-32. https://doi.org/10.1128/IAl.01308-07.

8. Mou X, Spinard EJ, Driscoll MV, Zhao W, Nelson DR. H-NS is a negative regulator of the two hemolysin/cytotoxin gene clusters in Vibrio anguillarum. Infect Immun. 2013;81(10):3566-76. https://doi.org/10.1128/ |Al.00506-13.

9. Rock JL, Nelson DR. Identification and characterization of a hemolysin gene cluster in Vibrio anguillarum. Infect Immun. 2006;74(5):2777-86. https://doi. org/10.1128/IAI.74.5.2777-2786.2006.

10. Naka H, Dias GM, Thompson CC, Dubay C, Thompson FL, Crosa JH. Complete genome sequence of the marine fish pathogen Vibrio anguillarum harboring the pJM1 virulence plasmid and genomic comparison with other virulent strains of $V$. anguillarum and $V$. ordalii. Infect Immun. 2011;79(7):2889-900. https://doi.org/10.1128/IAl.05138-11.

11. Li L, Mou X, Nelson DR. Characterization of Plp, a phosphatidylcholinespecific phospholipase and hemolysin of Vibrio anguillarum. BMC Microbiol. 2013:13:271. https://doi.org/10.1186/1471-2180-13-271.

12. Hoiseth SK, Stocker BAD. Aromatic-dependent Salmonella-Typhimurium are non-virulent and effective as live vaccines. Nature. 1981;291(5812):238-9. https://doi.org/10.1038/291238a0.

13. Bowe F, Ogaora P, Maskell D, Cafferkey M, Dougan G. Virulence, persistence, and immunogenicity of Yersinia enterocolitica $0: 8$ aroA mutants. Infect Immun. 1989:57(10):3234-6.

14. Roberts M, Maskell D, Novotny P, Dougan G. Construction and characterization in vivo of Bordetella pertussis aroA mutants. Infect Immun. 1990;58(3):732-9.

15. Homchampa P, Strugnell RA, Adler B. Molecular analysis of the AroA gene of Pasteurella multocida and vaccine potential of a constructed AroA mutant. Mol Microbiol. 1992;6(23):3585-93. https://doi.org/10.1111/j.13652958.1992.tb01794x

16. Lawrence ML, Cooper RK, Thune RL. Attenuation, persistence, and vaccine potential of an Edwardsiella ictaluri purA mutant. Infect Immun. 1997;65(11): 4642-51.

17. Mercado-Lubo R, Gauger EJ, Leatham MP, Conway T, Cohen PS. A Salmonella enterica serovar typhimurium succinate dehydrogenase/fumarate reductase double mutant is avirulent and immunogenic in BALB/c mice. Infect Immun. 2008;76(3):1128-34. https://doi.org/10.1128/IAI.01226-07.
18. Mercado-Lubo R, Leatham MP, Conway T, Cohen PS. Salmonella enterica serovar Typhimurium mutants unable to convert malate to pyruvate and oxaloacetate are avirulent and immunogenic in BALB/c mice. Infect Immun. 2009:77(4):1397-405. https://doi.org/10.1128/IAl.01335-08.

19. Utley M, Franklin DP, Krogfelt KA, Laux DC, Cohen PSA. Salmonella typhimurium mutant unable to utilize fatty acids and citrate is avirulent and immunogenic in mice. FEMS Microbiol Lett. 1998;163(2):129-34.

20. Yimga MT, Leatham MP, Allen JH, Laux DC, Conway T, Cohen PS. Role of gluconeogenesis and the tricarboxylic acid cycle in the virulence of Salmonella enterica serovar Tyhimurium in BALB/C mice. Infect Immun. 2006; 74(2):1130-40. https://doi.org/10.1128/lai.74.2.1130-1140.2006.

21. Valentine PJ, Devore BP, Heffron F. Identification of three highly attenuated Salmonella typhimurium mutants that are more immunogenic and protective in mice than a prototypical aroA mutant. Infect Immun. 1998; 66(7):3378-83.

22. Allen JH, Utley $M$, van Den Bosch $H$, Nuijten P, Witvliet M, McCormick BA, et al. A functional cra gene is required for Salmonella enterica serovar typhimurium virulence in BALB/C mice. Infect Immun. 2000;68(6):3772-5.

23. Dahal N, Abdelhamed $H$, Karsi A, Lawrence ML. Tissue persistence and vaccine efficacy of tricarboxylic acid cycle and one-carbon metabolism mutant strains of Edwardsiella ictaluri. Vaccine. 2014;32(31):3971-6. https:// doi.org/10.1016/j.vaccine.2014.05.016.

24. Dahal N, Abdelhamed H, Lu J, Karsi A, Lawrence ML. Tricarboxylic acid cycle and one-carbon metabolism pathways are important in Edwardsiella ictaluri virulence. PLoS One. 2013;8(6):e65973. https://doi.org/10.1371/J.pone. 0065973

25. Dahal N, Abdelhamed H, Lu J, Karsi A, Lawrence ML. Effect of multiple mutations in tricarboxylic acid cycle and one-carbon metabolism pathways on Edwardsiella ictaluri pathogenesis. Vet Microbiol. 2014;169(1-2):107-12. https://doi.org/10.1016/j.vetmic.2013.12.006

26. Alteri CJ, Smith SN, Mobley HL. Fitness of Escherichia coli during urinary tract infection requires gluconeogenesis and the TCA cycle. PLoS Pathog. 2009; 5(5):e1000448. https://doi.org/10.1371/J.ppat.1000448.

27. VanderVen BC, Fahey RJ, Lee W, Liu Y, Abramovitch RB, Memmott C, et al, Novel inhibitors of cholesterol degradation in Mycobacterium tuberculosis reveal how the bacterium's metabolism is constrained by the intracellular environment. PLoS Pathog. 2015;11(2):e1004679. https://doi.org/10.1371/J. ppat.1004679.

28. Vaatanen P. Microbiological studies in coastal waters of the northern Baltic Sea. I. Distribution and abundance of bacteria and yeasts in the Tvarminne area. Walter Andre Nottback found. Sci Rep. 1976:1:1-58.

29. Neidhardt FC, Bloch PL, Smith DF. Culture medium for enterobacteria. J Bacteriol. 1974:119(3):736-47.

30. Aziz R, Bartels D, Best a, DeJongh M, Disz T, Edwards R, et al. the RAST server: rapid annotations using subsystems technology. BMC Genomics. 2008;9(1):75.

31. Milton DL, O'Toole R, Horstedt P, Wolf-Watz H, Flagellin A. Is essential for the virulence of Vibrio anguillarum. J Bacteriol. 1996;178(5):1310-9.

32. Varina M, Denkin SM, Staroscik AM, Nelson DR. Identification and characterization of Epp, the secreted processing protease for the Vibrio anguillarum EmpA metalloprotease. J Bacteriol. 2008;190(20):6589-97. https://doi.org/10.1128/JB.00535-08.

33. Garcia T, Otto K, Kjelleberg S, Nelson DR. 1997. Growth of Vibrio anguillarum in salmon intestinal mucus. Appl. Environ. Microbiol. 1997;63(3):1034-9.

34. Marden P, Tunlid A, Malmcrona-Friberg K, Oldham G, Kjelleberg S. 1985. Physiological and morphological changes during short term starvation of marine bacterial isolates. Arch. Microbiol. 1985;142(4):326-32.

35. Ormonde $\mathrm{P}$, Horstedt $\mathrm{P}, \mathrm{O}$ 'Toole R, Milton DL. Role of motility in adherence to and invasion of a fish cell line by Vibrio anguillarum. J Bacteriol. 2000; 182(8):2326-8.

36. Lindell K, Fahlgren A, Hjerde E, Willassen NP, Fallman M, Milton DL. Lipopolysaccharide O-Antigen prevents phagocytosis of Vibrio anguillarum by rainbow trout (Oncorhynchus mykiss) skin epithelial cells. PLoS One. 2012; 7(5):e37678, https://doi.org/10.1371/J.pone.0037678.

37. Larsen MH, Boesen HT. Role of flagellum and chemotactic motility of Vibrio anguillarum for phagocytosis by and intracellular survival in fish macrophages. FEMS Microbiol Lett. 2001;203(2):149-52.

38. Wang $\mathrm{XH}$, Oon $\mathrm{HL}$, Ho GW, Wong WS, Lim TM, Leung KY. Internalization and cytotoxicity are important virulence mechanisms in Vibrio-fish epithelial cell interactions. Microbiol. 1998:144(Pt 11):2987-3002. https://doi.org/10. 1099/00221287-144-11-2987. 
39. Minato Y, Fassio SR, Wolfe AJ, Hase CC. Central metabolism controls transcription of a virulence gene regulator in Vibrio cholerae. Microbiol. 2013;159(Pt 4):792-802. https://doi.org/10.1099/mic.0.064865-0.

40. Li L, Mou X, Nelson DR. HlyU is a positive regulator of hemolysin expression in Vibrio anguillarum. J Bacteriol. 2011;193(18):4779-89. https://doi.org/10. 1128/JB.01033-10.

41. Live NDR. Avirulent strain of $V$. anguillarum that protects fish against infection by virulent $V$. anguillarum and method of making the same. U.S. patent 6913757 B1. July. 2005:5.

42. Crosa JHA. Plasmid associated with virulence in the marine fish pathogen Vibrio anguillarum specifies an iron-sequestering system. Nature. 1980; 284(5756):566-8.

43. Wolf MK, Crosa JH. Evidence for the role of a siderophore in promoting Vibrio anguillarum infections. J Gen Microbiol. 1986;132(10):2949-52.

44. O'Toole R, Lundberg S, Fredriksson SA, Jansson A, Nilsson B, Wolf-Watz H. The chemotactic response of Vibrio anguillarum to fish intestinal mucus is mediated by a combination of multiple mucus components. J Bacteriol. 1999;181(14):4308-17.

45. Muroga K, Delacruz MC. Fate and location of Vibrio anguillarum in tissues of artificially infected Ayu (Plecoglossus altivelis). Fish Pathol. 1987;22(2):99-103.

46. Altinok I, Capkin E, Karsi A. Succinate dehydrogenase mutant of Listonella anguillarum protects rainbow trout against vibriosis. Vaccine. 2015;33(42): 5572-7. https://doi.org/10.1016/j.vaccine.2015.09.003.

47. Denkin SM, Nelson DR. Induction of protease activity in Vibrio anguillarum by gastrointestinal mucus. Appl Environ Microbiol. 1999;65(8):3555-60.

48. Simon R, Priefer U, Puhler A. A broad host range mobilization system for in vivo genetic-engineering - transposon mutagenesis in gram-negative bacteria. Bio-Technol. 1983;1(9):784-91. https://doi.org/10.1038/Nbt1183-784.

49. McGee K, Horstedt P, Milton DL. Identification and characterization of additional flagellin genes from Vibrio anguillarum. J Bacteriol. 1996; 178(17):5188-98.

\section{Submit your next manuscript to BioMed Central and we will help you at every step:}

- We accept pre-submission inquiries

- Our selector tool helps you to find the most relevant journal

- We provide round the clock customer support

- Convenient online submission

- Thorough peer review

- Inclusion in PubMed and all major indexing services

- Maximum visibility for your research

Submit your manuscript at www.biomedcentral.com/submit

) Biomed Central 